\title{
Migratory patterns and population redistribution in China's Zhoushan Archipelago in the context of rapid urbanization
}

\author{
Wenze Yue
}

Department of Land Management, Zhejiang University, China

wzyue@zju.edu.cn

Shuangshuang Qiu

Department of Land Management, Zhejiang University, China

ssqiu@zju.edu.cn

\author{
Huan Zhang \\ College of Civil Engineering and Architecture, Zhejiang University, China \\ 0014979@zju.edu.cn (corresponding author)
}

and

\author{
Jiaguo Qi \\ Michigan State University, East Lansing MI 48824, USA. \\ qi@msu.edu
}

\begin{abstract}
China's rapid urbanization has not only resulted in significant economic development but has also introduced various social problems and encouraged human migration. Chinese islands are not immune to these changes. Aspects of island geography and environment mean that island migration has some unique characteristics and underlying drivers. Most recent studies have focused on mainland migration, but few attempts have been made to examine island migration. This paper bridges this gap by focusing on the Zhoushan Archipelago and combines qualitative and quantitative methods to explore the characteristics and causes of migration. The results show that (i) Zhoushan's population is more concentrated in developed towns and larger islands, (ii) inter-island and island-mainland migrations are the two dominant migration types, and (iii) the main drivers for migration are exhaustion of fishery resources and policy implementation by multi-level governments.
\end{abstract}

Keywords: archipelagos, China, island cities, population migration, urbanization, Zhoushan

https://doi.org/10.24043/isj.23

C 2017 - Institute of Island Studies, University of Prince Edward Island, Canada.

\section{Introduction}

China has experienced rapid urbanization over the past three decades. The proportion of urban residents in China increased from $19.39 \%$ in 1980 to $36.22 \%$ in 2000 and $54.77 \%$ in 2014, with an annual growth rate of $1.43 \%$ from 2000 to 2014 (NBS, 2014). The proportion of urban residents in China is expected to rise to about two-thirds of the total population by 2030 (World Bank and DRCSC, 2013). China's social needs and historical context indicate that its urbanization process has been subjected to unique dynamics (Chen et al., 2013; Zhang \& Zhao, 2003). 
Combined studies on island urbanization and population migration have been scarce until recently, with many existing studies focusing on historical migration or newer studies using qualitative methodologies. Islands are relatively closed, fragile, ecologically sensitive, and transition zones between the land and ocean, which have a profound effect on human survival and development. Population is an important factor in the social and economic development of inhabited islands (Zhao et al., 2012) and is known to flow among islands that differ in area, location, and development. Studies on island urbanization and population migration are not only beneficial to the development of the marine economy and sustainable utilization of islands but also important for border security and maritime rights and interests.

Taking the Zhoushan Archipelago in the northeastern seas in China's Zhejiang Province as our focus, this paper combines qualitative and quantitative methods to discuss the characteristics and causes of island population migration in the process of urbanization. By providing a better description of the relationship between population, islands, and urbanization policy, we can direct future research and policy-making more effectively.

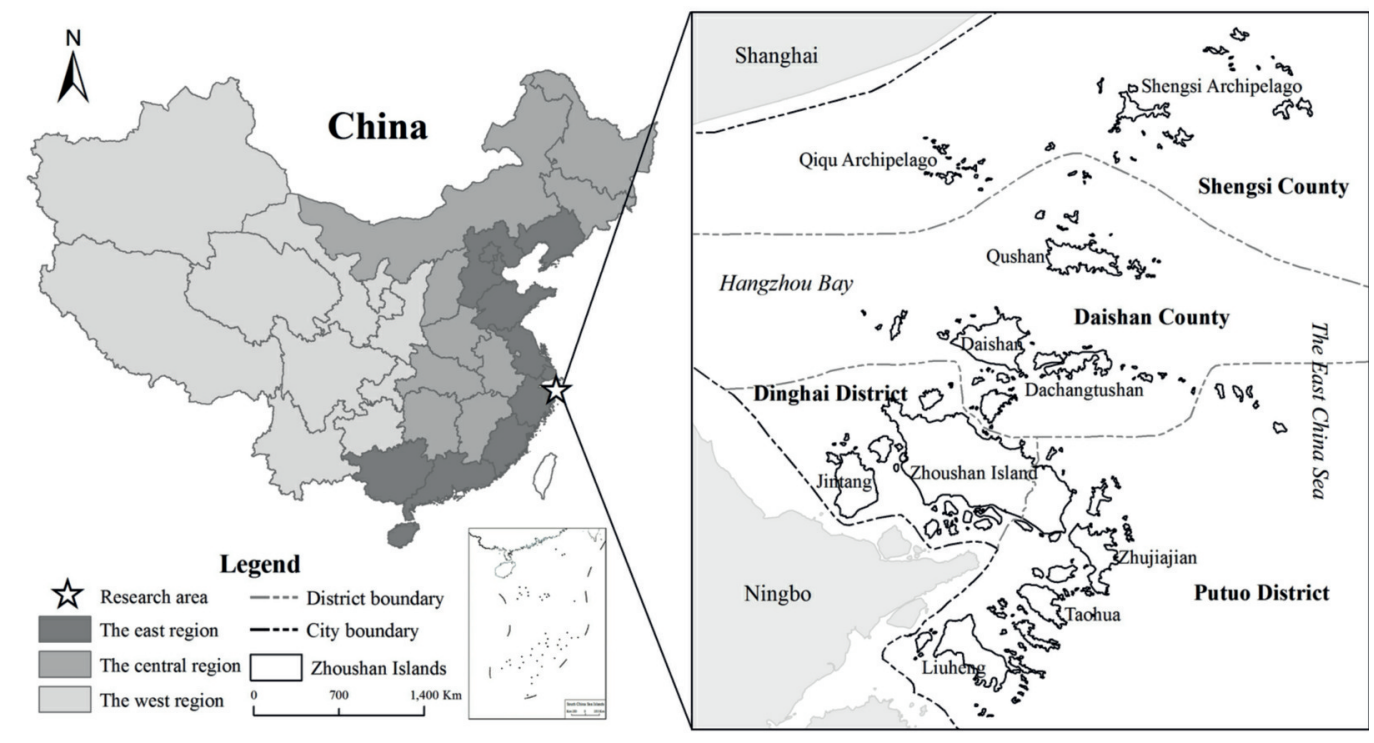

Figure 1: Study area.

\section{Literature review}

China's urbanization has been studied extensively from economic, geographic, and planning perspectives (Chaolin et al., 2012; Chen \& Gao, 2011; Friedmann, 2006; Lin, 1998, 2007; Shen et al., 2006). Urbanization over the past decades has been viewed in terms of many people migrating from rural to urban areas and from inland to coastal areas. This directed population flow has resulted in profound changes in China's social structures and introduced social problems, including peasant workers and 'hollow' villages while at the same time promoting national economic development (Guo, 2014). Similarly, although island urbanization has boosted some local economies, island migration has led to 'hollow' islands and villages. 'Island migration' is here defined as intra-island migration (migration within an island), inter-island migration (migration between islands in an archipelago), and island-mainland migration.

Island spatialities and natural environments are known to affect migration. Previous studies show that people living on islands with poor living conditions or fishery resources are more inclined to migrate (Burholt et al., 2013; Chand, 2005; Zhang, 2012). At the same time, certain island spatialities encourage urbanization and densification (Grydehøj, 2015; Steyn, 2015). Island population dynamics and underlying reasons for rapid urbanization thus differ to those that affect the mainland. It is thus important to understand these factors to direct decision making for sustainable island development. 
Existing studies on migration have focused on migration and urbanization (Kojima, 1996), spatial features (G. Wang et al., 2012), migration policies (Epstein \& Nitzan, 2006), and underlying reasons for migration (Stark et al., 2009). Relevant theories include Ravenstein's (1885) seven laws of migration, Zipf's (1946) gravity model, Lee's (1966) push-pull theory, and the neoclassical theory proposed by Massey et al. (1994). Most researchers attribute migration to changes in economy, policy, and society (Black et al., 2012; Lai et al., 1995; Lonergan, 1998), while some favour the dominance of environmental change (Byravan \& Rajan, 2006; Jacobson, 1988; Mcleman \& Smit, 2006; Myers, 2001, 2002). Most existing studies focus on migration between mainland cities or regions, and few attempts have been made to study island migration. We work to bridge this knowledge gap.

Within the field of island studies, attention has been paid to the role of islands as places of transition and to their political use as exceptional spaces for receiving migrants (Baldacchino, 2014; Briskman et al., 2012; Friese, 2012; Loyd \& Mountz, 2014; Triandafyllidou, 2014). Only recently has the field opened up to explicitly urban perspectives (Grydehøj et al., 2015), including perspectives that focus on how island urbanization alters maritime activities and land-ocean relationships (Hayward, 2015). Many existing island population migration studies utilize archaeological or genetic data to reveal ancient or prehistoric migration features but tend to ignore recent migration (Carson \& Hung, 2014; Fitzhugh et al., 2016; Helgason et al., 2006; Shaw et al., 2009). For instance, based on studies of two migrations related to Taiwan, Carson and Hung (2014) develop their 'semiconductor theory', wherein the island could be the receiver, the homeland, or the gateway for migration. With respect to research methodology, questionnaires and interviews are often utilized to examine sociological perspectives on migration (Burholt et al., 2013; Liu, 2014; Mortreux \& Barnett, 2009). For example, Burholt et al. (2013) conducts a field survey of two islands in Ireland by means of in-depth interviews and a semi-structured questionnaire to explore the reasons behind migration.

Migration features vary on different islands. In China's Changshan Archipelago, the main pattern of migration is population emigration, with migration from small to large islands or to the mainland (Wang, 2004). In contrast, Zhoushan Archipelago has experienced population concentration on larger islands, an increasing floating population, the migration of educated youths to the mainland, and generally greater inflow than outflow (J. Wang et al., 2012).

The reasons for island migration can be grouped as follows. First, urbanization and economic development promote transformation and development of island industry. Local labour shifts gradually from primary industries to secondary and tertiary industries, with a simultaneous significant inflow of external migrants (Wang, 2004), which may be associated with greater economic strength (Guan \& McElroy, 2012). Second, government policies tend to encourage migration and population concentration (J. Wang et al., 2012). Third, island living conditions have become less favourable because of climate change, with existing public infrastructure on some islands already inadequate for local needs (Burholt et al., 2013; Fitzhugh et al., 2016). The effect of climate change on island population migration has been discussed extensively, with Pacific island countries gradually becoming the research focus (Campbell, 2010; Chand, 2005; Farbotko, 2010; Locke, 2009; Mortreux \& Barnett, 2009). Campbell (2010) proposes two types of migration in Pacific island countries caused by climate change and suggests that the flow direction could be internal as well as external. In contrast, in a study on Tuvalu, Mortreux and Barnett (2009) suggest that the main reason for migration is not climate change but rather household income, age, and number and age of children.

\section{Data and methods}

\section{Study area}

Zhoushan Archipelago $\left(29^{\circ} 32^{\prime}-31^{\circ} 04^{\prime} \mathrm{N}, 121^{\circ} 30^{\prime}-123^{\circ} 25^{\prime} \mathrm{E}\right)$, a hilly island region with a subtropical monsoon climate, is located in the northeastern seas of Zhejiang Province in China. It is at the intersection of China's eastern coastline and the Yangtze River waterway. As China's largest archipelago, Zhoushan has 1,390 islands with a total sea and land area of 22,000 km $\mathrm{km}^{2}$ and $1,371 \mathrm{~km}^{2}$ respectively. The archipelago's main islands are Zhoushan, Daishan, Qushan, Zhujiajian, Liuheng, 
and Jintang, among which Zhoushan Island is the largest with a land area of $502.65 \mathrm{~km}^{2}$. The archipelago is divided into two districts (Dinghai and Putuo) and two counties (Daishan and Shengsi). For convenience, these counties and districts are collectively referred to as 'districts' below.

According to the latest census in 2010 (NBS, 2011), Zhoushan Archipelago supported a permanent resident population of about 1,121,300 people, of which $63.59 \%$ were urban, a proportion $2 \%$ higher than that of Zhejiang Province as a whole. Since the end of the 20th century, Zhoushan has devoted efforts to developing its harbor industry. In 2011, China's State Council established Zhoushan as a National District with the theme of marine economy. As a result, the proportion of Zhoushan's industrial output increased from $29.6 \%$ in 2000 to $44.2 \%$ in 2013, with an annual growth rate of nearly $1 \%$, and the added value of its marine economy accounted for $69.10 \%$ of Zhoushan's GDP (Gross Domestic Product) by 2013. Consequently, Zhoushan Archipelago has undergone a gradual industrial transformation and continually strengthening mainland-island contact (Qiu et al., 2017).

\section{Methods}

The quantitative methods of rank-size rule and indices as well as a qualitative literature search were utilized. Data utilized in the quantitative analysis were from the fifth and sixth census data in 2000 (NBS, 2001) and 2010, the Zhoushan Statistical Yearbooks of 2002 (Zhoushan Bureau of Statistics, 2002) and 2015 (Zhoushan Bureau of Statistics, 2015), and vector data of administrative divisions in 2010. Because of the huge adjustments in Zhoushan's administrative divisions over the decade, the 2000 data were adjusted to make the population data comparable between time points. Data utilized in the semi-qualitative analysis included agriculture and fishery census data in 2006 from Zhoushan Statistical Yearbook (Zhoushan Bureau of Statistics, 2015), the sixth census data in 2010 (NBS, 2011), and the literature (J. Wang et al., 2012).

First, because an archipelago system with many large and small islands is similar to an urban system with many cities, the rank-size rule was utilized to explore variations in population size distribution from two perspectives of the town and island, to reveal overall migratory trends. This rule was originally utilized to study the size distribution of an urban system according to the relationship between city size and city size rank (Beckmann, 1958). Zipf (1946) showed that the product of a city size and its size rank was equal to the size of the city ranked first. The more generalized Lotka model added a power exponent to the variable of city size rank as an elastic coefficient to provide stronger universality (Chen, 2004; Qi \& Liu, 2015).

$$
P_{i}=P_{1} \times R_{i}^{-q}
$$

Generally, Equation (1) is logarithmically transformed to

$$
\lg P_{i}=\lg P_{1}-q \lg R_{i}
$$

where $P_{i}$ is the population of the town/island ranked $\mathrm{i}-\mathrm{th}$; $P_{1}$ is the population of the top-ranked town/island; $R i$ is the size rank of the town/island ranked $\mathrm{i}$-th; $\mathrm{q}$ is a constant parameter called the Zipf Index; and $i=1,2, \ldots, n$. Scatter plots with unified linear regression were drawn to reveal the population size distribution of towns and islands. Many empirical studies have shown that the constant parameter $\mathrm{q}$ has the following attributes: when $\mathrm{q}=1$, the size distribution of an urban system is optimal; when $\mathrm{q}<1$, the population is uniformly distributed and the size distribution is more dispersed; when $\mathrm{q}>1$, the population is distributed with great difference and the size distribution is more concentrated; when q increases gradually, the size distribution tends to be concentrated; when q decreases gradually, the size distribution tends to be dispersed (Chen \& Liu, 1999; Xu et al., 2009).

Second, we analysed migratory directions with the help of indices and previous literature. The number of people immigrating and emigrating to/from each town over the decade was computed according to the fifth and sixth census data. The immigrating population represents the floating population change, whereas the emigrating population represents the floating population change minus 
the total population change after removing the influence of the natural population growth (data for which are provided by Zhoushan Statistical Yearbook; Zhoushan Bureau of Statistics, 2015). Based on these definitions and assumptions, the population migration index (PMI) is computed as follows:

$$
P M I=\frac{P_{E}-P_{I}}{P_{2000}} \times 100 \%
$$

where $P E$ is the emigrating population; $P I$ is the immigrating population; and $P 2000$ is the total population in 2000. Based on the PMI, all towns in Zhoushan Archipelago were classified into five types, including the vital immigration place, general immigration place, steady place, general emigration place, and vital emigration place. Hence, migratory directions can be revealed when supplemented by previous literature.

\section{Characteristics of population migration in Zhoushan Archipelago}

Population distribution in 2000 and 2010

The population of each district in 2000 and 2010 is presented in Table 1. In 2000, Zhoushan had $1,001,530$ people, with about three people in each household on average, with the elderly population over 64 years old and the floating population accounting for $9.33 \%$ and $20.59 \%$ respectively. In 2010 , the total population increased to $1,121,261$, with a growth rate of $11.95 \%$, while the average number of people per household decreased to about two. The proportion of the elderly population reached $10.50 \%$, indicating a slightly aging population. Meanwhile, the proportion of the floating population reached $38.63 \%$, showing a remarkably high growth rate of $109.98 \%$.

Table 1: Population of each district in 2000 and 2010.

\begin{tabular}{|l|l|l|l|l|l|l|l|}
\hline Year & District & Total pop. & $\begin{array}{l}\text { Pop. } \\
\text { over 64 }\end{array}$ & $\begin{array}{l}\text { Floating } \\
\text { pop. }\end{array}$ & $\begin{array}{l}\text { Total } \\
\text { pop. (\%) }\end{array}$ & $\begin{array}{l}\text { Pop. over } \\
64)\end{array}$ & $\begin{array}{l}\text { Floating } \\
\text { pop. (\%) }\end{array}$ \\
\hline 2000 & Dinghai & 369,448 & 35,129 & 93,878 & 36.89 & 9.51 & 25.41 \\
\hline & Putuo & 346,237 & 30,697 & 75,046 & 34.57 & 8.87 & 21.67 \\
\hline & Daishan & 197,483 & 19,952 & 22,812 & 19.72 & 10.10 & 11.55 \\
\hline & Shengsi & 88,362 & 7626 & 14,529 & 8.82 & 8.63 & 16.44 \\
\hline & Total & $\mathbf{1 , 0 0 1 , 5 3 0}$ & $\mathbf{9 3 , 4 0 4}$ & $\mathbf{2 0 6 , 2 6 5}$ & $\mathbf{1 0 0}$ & $\mathbf{9 . 3 3}$ & $\mathbf{2 0 . 5 9}$ \\
\hline 2010 & Dinghai & 464,184 & 45,739 & 202,616 & 41.4 & 9.85 & 43.65 \\
\hline & Putuo & 378,805 & 39,289 & 151,568 & 33.78 & 10.37 & 40.01 \\
\hline & Daishan & 202,164 & 23,865 & 62,348 & 18.03 & 11.80 & 30.84 \\
\hline & Shengsi & 76,108 & 8877 & 16,582 & 6.79 & 11.66 & 21.79 \\
\hline & Total & $\mathbf{1 , 1 2 1 , 2 6 1}$ & $\mathbf{1 1 7 , 7 7 0}$ & $\mathbf{4 3 3 , 1 1 4}$ & $\mathbf{1 0 0}$ & $\mathbf{1 0 . 5 0}$ & $\mathbf{3 8 . 6 3}$ \\
\hline
\end{tabular}

Notes: Pop. refers to population. The total pop. (\%) refers to the proportion of the total population of each district in that of Zhoushan. Pop. over 64 (\%) refers to the proportion of the population over 64 years old in the total population of each district. Floating pop. (\%) refers to the proportion of the floating population in the total population of each district.

Figure 2 presents the population distributions of each district in 2000 and 2010 . Over $70 \%$ of the total population was concentrated in Dinghai and Putuo in a polycentric pattern. Over the decade, the population in these two districts agglomerated gradually. In 2000, the total population of Daishan and Shengsi slightly surpassed that of Dinghai, whereas in 2010, it was less than 75\% of that of Putuo. In 2000, the elderly population of just over half of the total 43 towns accounted for over 
$10 \%$, whereas in 2010 , its proportion was over $10 \%$ in nearly $70 \%$ of towns. The elderly population was greater in the archipelago's eastern and northern regions. The floating population was distributed mainly in Dinghai and Putuo. The number of towns whose floating population accounted for over 30\% increased from 6 in 2000 to 19 in 2010, and in 2010, about 25\% of the towns' floating populations even surpassed $50 \%$. The floating population preferred all districts except for Shengsi.

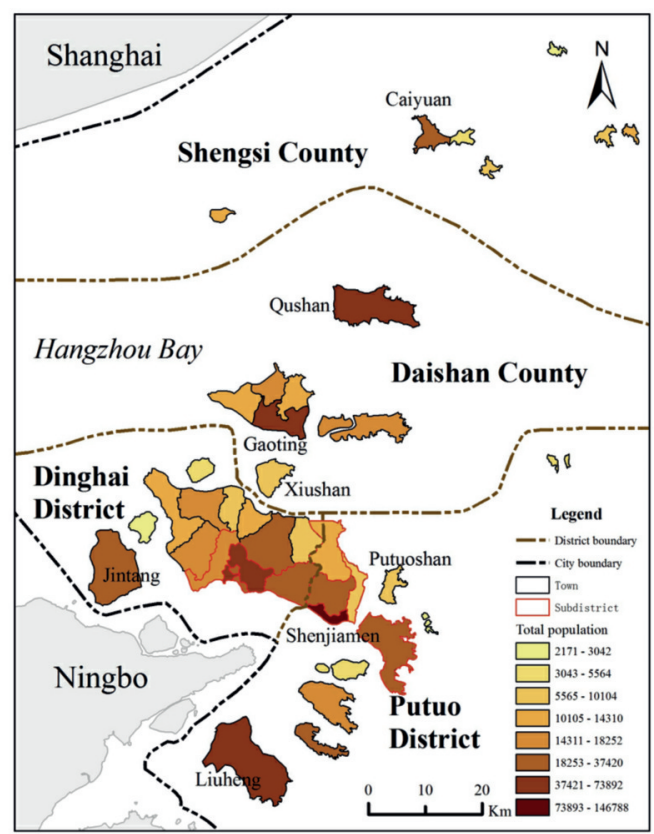

(A) 2000

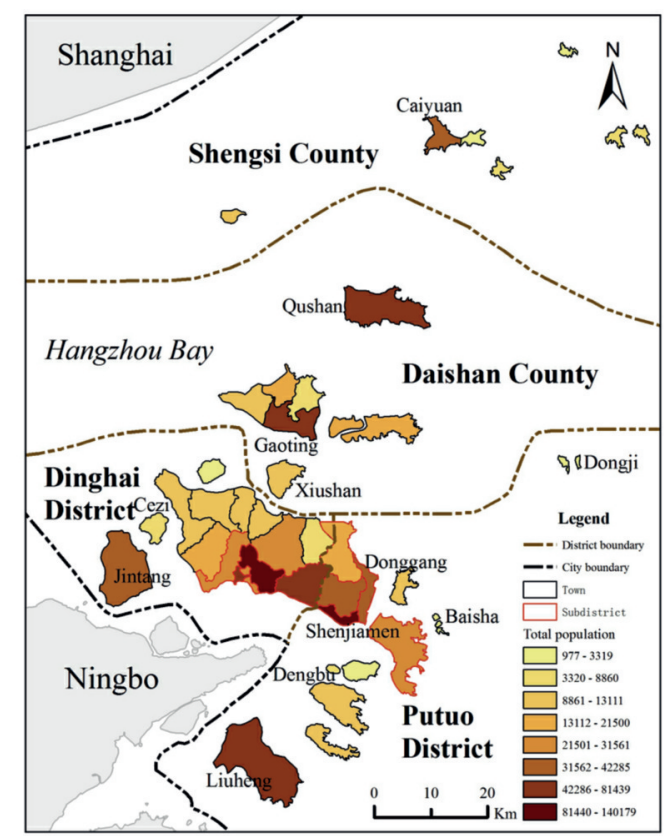

(B) 2010

Figure 2: Population distribution of each district in 2000 and 2010.

Overall migratory trends

Variations in population size distribution in Zhoushan Archipelago's towns and islands were analysed by means of the rank-size rule to reveal overall migratory trends. Table 2 shows the calculation results of unified linear regression analyses.

Table 2: Calculation results of unified linear regression analyses.

\begin{tabular}{|l|l|l|l|l|l|l|l|l|l|}
\hline $\begin{array}{l}\text { Regression } \\
\text { analysis }\end{array}$ & Year & $\mathrm{R}^{2}$ & F-test & & Constant & & $\begin{array}{l}\text { Coefficient } \\
\text { of lgR }\end{array}$ & & $\begin{array}{l}\text { Regression } \\
\text { model }\end{array}$ \\
\hline & & & F & Sig. & Value & Sig. & Value & Sig. & \\
\hline $\begin{array}{l}\text { Town } \\
\text { lgP \& lgR) }\end{array}$ & 2000 & 0.881 & 304.502 & 0.000 & 5.399 & 0.000 & -0.993 & 0.000 & $\begin{array}{l}\mathrm{y}=-0.993 \mathrm{x}+ \\
5.399\end{array}$ \\
\hline & 2010 & 0.790 & 154.570 & 0.000 & 5.622 & 0.000 & -1.186 & 0.000 & $\begin{array}{l}\mathrm{y}=-1.186 \mathrm{x}+ \\
5.622\end{array}$ \\
\hline $\begin{array}{l}\text { Island } \\
\text { lgP \& lgR) }\end{array}$ & 2000 & 0.918 & 826.831 & 0.000 & 6.382 & 0.000 & -2.231 & 0.000 & $\begin{array}{l}\mathrm{y}=-2.231 \mathrm{x}+ \\
6.382\end{array}$ \\
\hline & 2010 & 0.952 & 1397.952 & 0.000 & 6.407 & 0.000 & -2.299 & 0.000 & $\begin{array}{l}\mathrm{y}=-2.299 \mathrm{x}+ \\
6.407\end{array}$ \\
\hline $\begin{array}{l}\text { Island } \\
\text { pop. \& area }\end{array}$ & 2000 & 0.887 & 579.719 & 0.000 & -1230.149 & 0.499 & 805.622 & 0.000 & $\begin{array}{l}\mathrm{y}=805.622 \mathrm{x}- \\
1230.149\end{array}$ \\
\hline & 2010 & 0.880 & 521.994 & 0.000 & -3129.646 & 0.200 & 999.621 & 0.000 & $\begin{array}{l}\mathrm{y}=999.621 \mathrm{x}- \\
3129.646\end{array}$ \\
\hline
\end{tabular}

Regression analyses of the towns' population sizes and ranks are shown in Figures 3A and 3B respectively. In 2000, the absolute value of the slope was less than and close to one, indicating that 
the population was uniformly distributed in towns. The development of larger towns was not prominent, but the development of small and medium-sized towns was relatively better. The actual size of the top-ranked town was smaller than its ideal size, with room for development. In contrast, in 2010, the absolute value of the slope was larger than one, indicating that the population distribution in towns differed greatly. Size distribution was concentrated: the development of larger towns was very prominent, but the development of small and medium-sized towns was insufficient. Over the decade, the absolute value of the slope became larger, indicating that the size distribution of towns tended to be concentrated and that the differences between the towns' scales expanded.

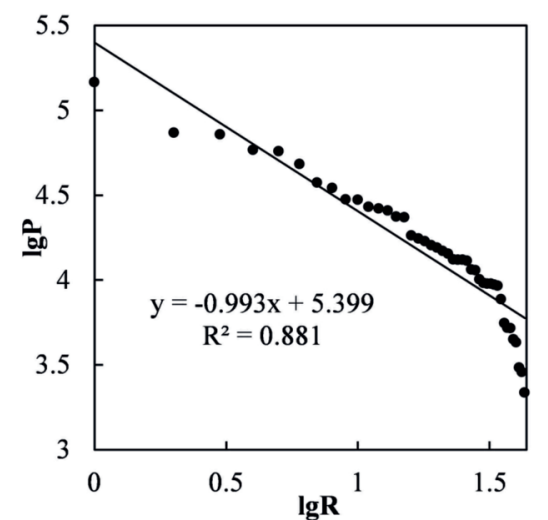

(A) 2000

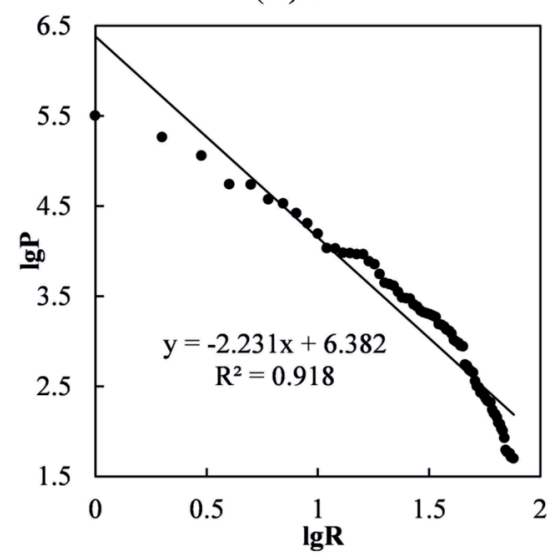

(C) 2000

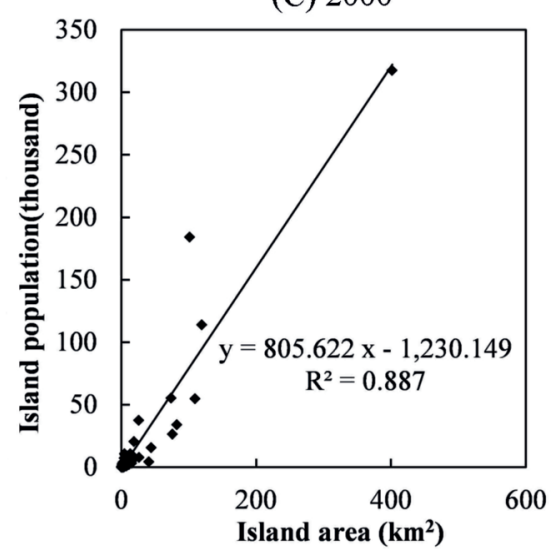

(E) 2000

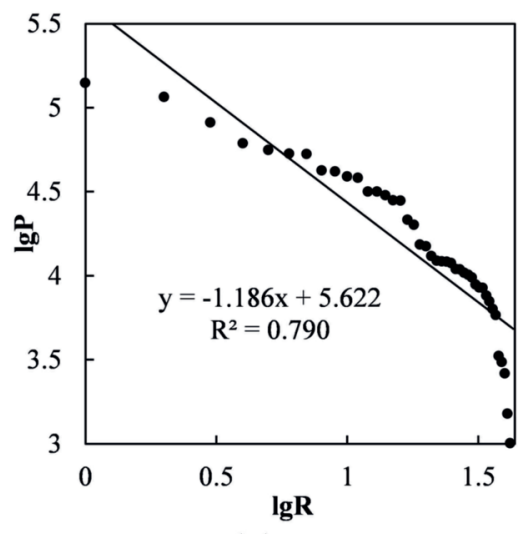

(B) 2010

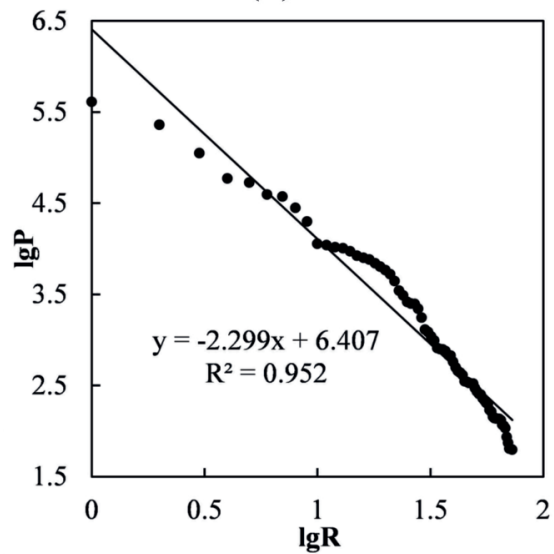

(D) 2010

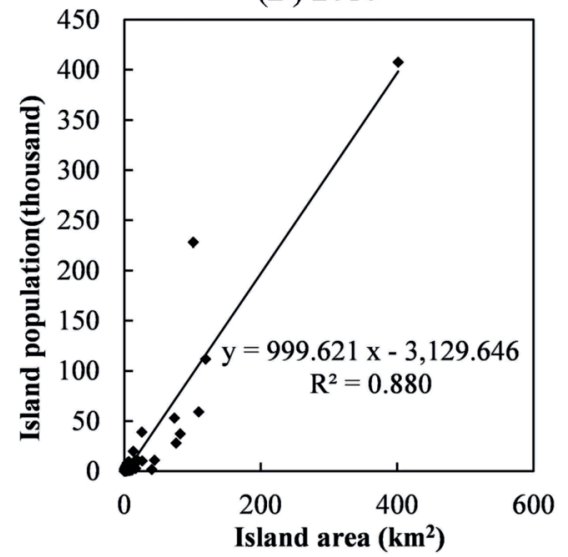

(F) 2010

Figure 3: Variations in population size distribution. Notes: (A) and (B) are the rank-size analyses of towns in 2000 and 2010, respectively; (C) and (D) are the rank-size analyses of islands in 2000 and 2010 respectively; and (E) and (F) are the scatter plots of island area and population in 2000 and 2010 respectively. 
Regression analyses of the islands' population sizes and ranks are shown in Figures $3 \mathrm{C}$ and 3D respectively. The absolute values of the slopes in 2000 and 2010 were both larger than two, indicating that the islands' population distributions at both points in time were very different and that the size distributions tended toward the first-place distribution. The development of large islands was extremely prominent, but the development of small islands was highly insufficient, and the actual size of the top-ranked island was much smaller than its ideal size, with plenty of room for development. Over the decade, the absolute value of the slope increased slightly, indicating that the islands' size distribution tended to be concentrated and that the first-place distribution strengthened. This increase was further emphasized in the scatter plots of island area and population (Figures 3E and $3 \mathrm{~F}$ respectively). Zhoushan Archipelago has a large number of small islands but only a few large islands. Island area was positively correlated with island population. Over the decade, the slope of the regression line increased, indicating that the population growth of large islands was greater than that of small islands and that the population gradually concentrated on large islands.

Towns' and islands' variations in total population generally resembled the size distribution features described above. The populations of larger towns gradually increased while the populations of small and medium-sized towns decreased. The populations of Dinghai and Putuo Islands both increased by over $20 \%$ while small and medium-sized islands had less obvious population growth, with some remote and small islands having decreasing populations. Finally, the slope of the regression line of islands was twice that of towns, indicating that the development of islands had a stronger polarization effect and that Zhoushan Archipelago' development focused more on islands than it did on towns.

Detailed analysis of population migration

The natural population growth rate of Zhoushan has always been low, with an annual growth rate of $-0.33 \%$ over the decade. With the exception of Dinghai, the populations of other districts all decreased naturally, with a total reduction of 2,748 people. Nevertheless, because of a large growth in floating population, the total population of Zhoushan still increased.

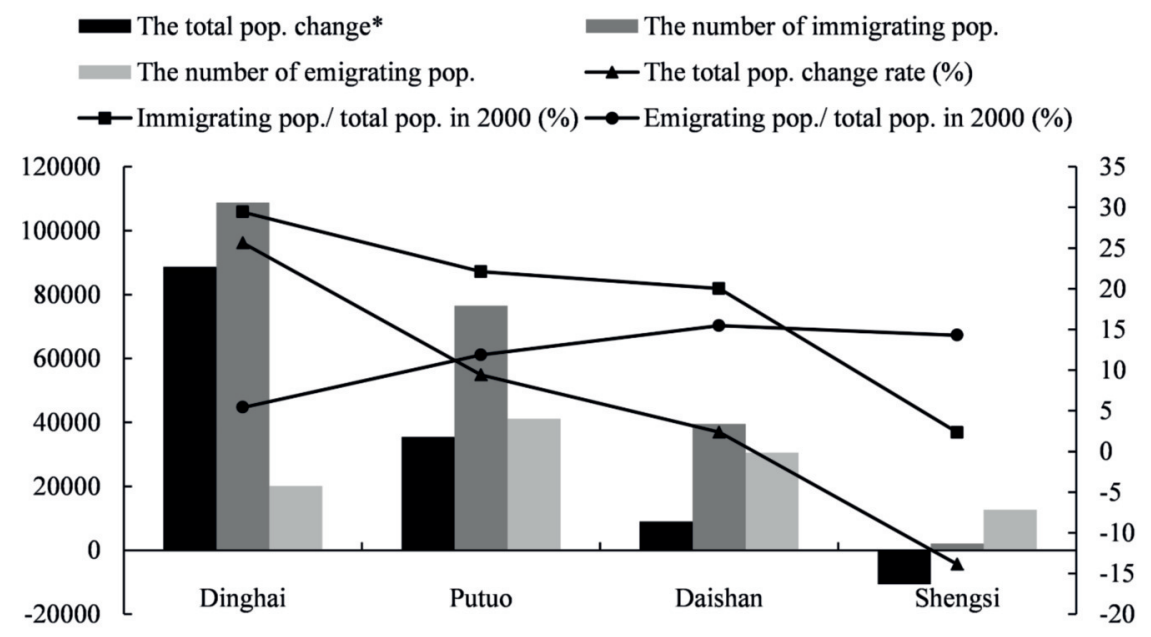

Figure 4: Variation in population in each district from 2000 to 2010. Note: Pop. refers to population; total pop. change ${ }^{\star}$ refers to change in total population after removing the effect of the natural population growth, i.e. only under the influence of population migration.

Figure 4 shows each district's variation in population. After removing the effect of natural population growth, only Shengsi's total population decreased while all other districts' total populations increased, with Dinghai showing the largest population growth. The immigrating population and its proportion to the total population in 2000 were greatest in Dinghai and Putuo, while the emigrating population was greatest in Putuo and Daishan and its proportion was greatest 
in Daishan and Shengsi. Overall, Dinghai and Shengsi were the main sites of immigration and emigration respectively, while variations in population of Daishan and Putuo were much smaller.

With a lack of natural population growth data for each town, and given the low growth rate, we assumed the total population change of each town could be attributed to migration. Over the decade, the total populations of nearly half the towns decreased: Most of these towns, such as Huaniao and Dongji, had relatively small populations and underdeveloped economies. Among the towns with an increase in the total population, Donggang's growth rate surpassed $300 \%$. Population immigration occurred in about $80 \%$ of towns. Towns with larger immigrating populations were located mainly in Dinghai and Putuo, including some sub-districts and more developed towns. Population emigration also occurred in over $85 \%$ of towns, among which Shenjiamen, Xiazhi, and Gaoting experienced the most emigration. Moreover, in accordance with each town's PMI, all towns in the archipelago were classified into five types (Table 3). Population migration was relatively prominent in towns with absolute PMI values greater than $10 \%$, and towns with absolute PMI values over $40 \%$ represented the leading towns for migration.

The below analysis only assessed net population migration, not the origins or destinations of migrants. Based on the quantitative results, we therefore performed semi-qualitative analysis of the migration directions by means of relevant data and literature. Population migration in Zhoushan Archipelago consisted of three main types: intra-island migration (migration within an island), inter-island migration (migration between islands in the archipelago), and islandmainland migration. Inter-island migration and island-mainland migration were the two major types. Details of the population migration within Zhoushan Archipelago can be found in Figure 5.

Table 3: Migration types of towns.

\begin{tabular}{|l|l|l|}
\hline Migration types & Criterion & Towns \\
\hline Vital immigration place & PMI $\geq-40 \%$ & $\begin{array}{l}\text { Donggang, Cezi, Lincheng, Goushan, } \\
\text { Chengdong, Yancang, Changtu, Zhanmao }\end{array}$ \\
\hline General immigration place & $-40 \%<$ PMI $<-10 \%$ & $\begin{array}{l}\text { Mayidao, Xiushan, Changguo, Ma'ao, } \\
\text { Huannan, Gaoting, Jiefang }\end{array}$ \\
\hline Steady place & $-10 \% \leq$ PMI $\leq 10 \%$ & $\begin{array}{l}\text { Jintang, Putuoshan, Ganlan, Baiquan, } \\
\text { Zhujiajian, Liuheng, Caiyuan, Shenjiamen, } \\
\text { Beichan, Qushan, Daixi, Cenggang }\end{array}$ \\
\hline General emigration place & $10 \%<$ PMI $<40 \%$ & $\begin{array}{l}\text { Shuangqiao, Dongsha, Gouqi, Xiaosha, } \\
\text { Yangshan, Shengshan, Huanglong, } \\
\text { Taohua, Changbai, Daidong, Wulong }\end{array}$ \\
\hline Vital emigration place & PMI $\geq 40 \%$ & \begin{tabular}{l} 
Xiazhi, Dengbu, Huaniao, Baisha, Dongji \\
\hline
\end{tabular}
\end{tabular}

According to the agriculture and fishery census data in 2006 (Zhoushan Bureau of Statistics, 2015) (Table 4), 60,267 people migrated for work from villages and were mainly males (70.13\%) and young adults $(84.09 \%)$. They generally no longer engaged in the primary industry but had shifted to secondary $(49.56 \%)$ and tertiary $(46.83 \%)$ industries. This population mostly migrated to other villages within the town $(64.45 \%)$ and other towns within the city $(18.76 \%)$, representing intra-island and inter-island migration in the archipelago. Intra-island migration generally involved migration from remote, inhospitable, and unsustainable villages to more economically developed villages or towns on the same island. For instance, the populations of Mamu, Yandun, and Dasha migrated to urban areas of Zhoushan Island (J. Wang et al., 2012). Inter-island migration generally involved migration from small to large islands. Within Zhoushan Archipelago, this type of migration included migration from the Ma'an and Qiqu Archipelagos to Caiyuan, from Xiaohuanglong to Dahuanglong Island, from islands near Qushan Island to Daodou, from islands near Daishan Island to Gaoting and urban areas in Putuo, and from islands near Liuheng and Xiazhi to urban areas in Putuo (J. Wang et al., 2012). 
Wenze Yue et al.

Table 4: Population who sought work away from villages in 2006.

\begin{tabular}{|l|l|l|l|l|l|}
\hline Destination & Zhoushan & Dinghai & Putuo & Daishan & Shengsi \\
\hline Other villages inside the town & 38,845 & 22,141 & 12,049 & 3876 & 779 \\
\hline Other towns inside the city & 11,305 & 5617 & 2549 & 2366 & 773 \\
\hline Other cities in the province & 6052 & 1432 & 2747 & 1450 & 423 \\
\hline Outside the province & 3379 & 1852 & 718 & 576 & 233 \\
\hline Hong Kong, Macau, Taiwan, Abroad & 686 & 223 & 400 & 51 & 12 \\
\hline Total & $\mathbf{6 0 , 2 6 7}$ & $\mathbf{3 1 , 2 6 5}$ & $\mathbf{1 8 , 4 6 3}$ & $\mathbf{8 3 1 9}$ & $\mathbf{2 2 2 0}$ \\
\hline
\end{tabular}

Note: These data are from the agriculture and fishery census of Zhoushan Archipelago in 2006.

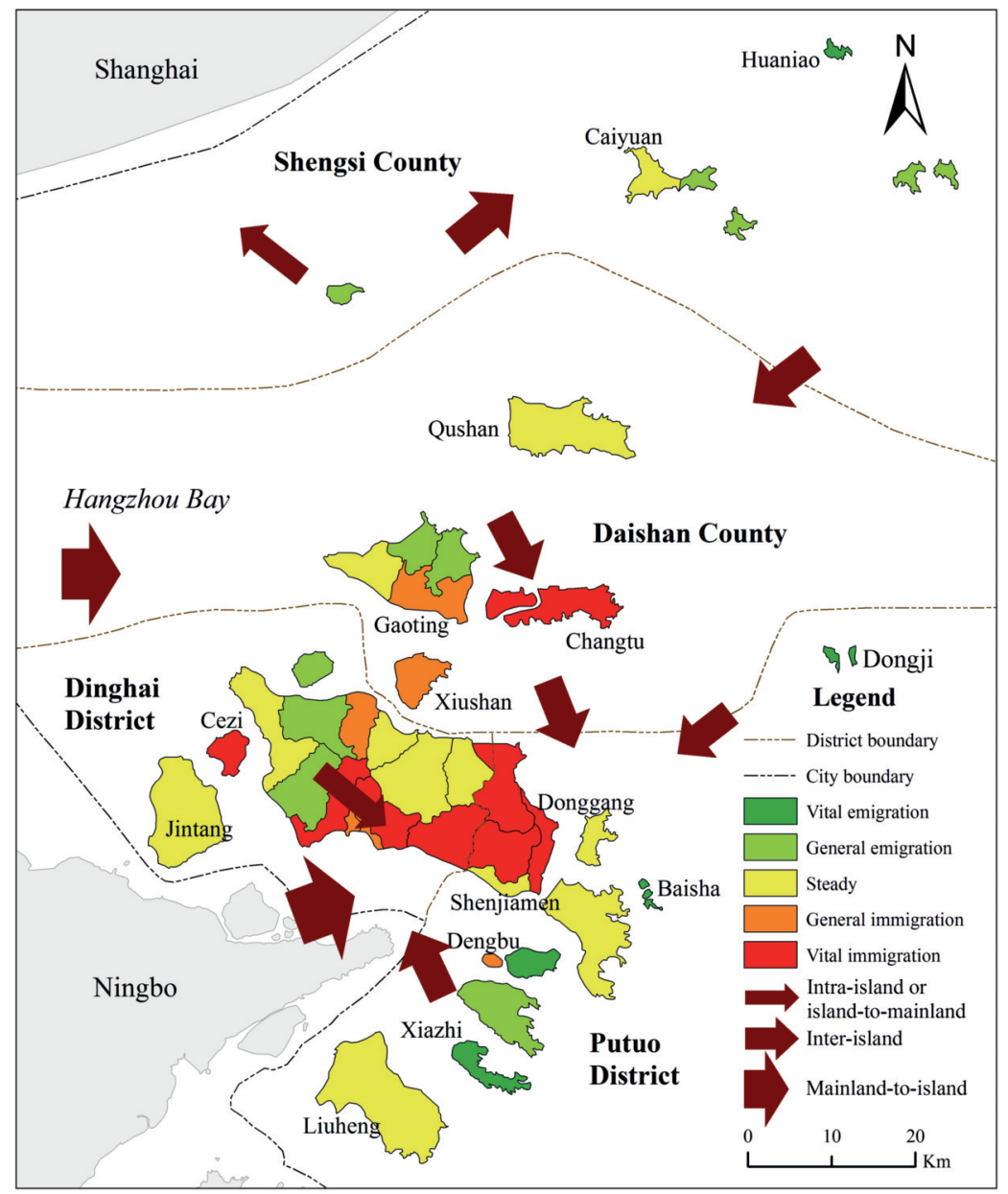

Figure 5: Population migration in Zhoushan Archipelago from 2000 to 2010.

\section{Discussion}

Zhoushan Archipelago has undergone gradual industrial transformation and strengthened mainland-island contact. Large inter-island differences in locations and resources have resulted in uneven economic development. For instance, the GDPs of Dinghai and Putuo have always been around $70 \%$ that of Zhoushan Island. Islands with leading industries and more developed economies were more attractive than islands with weaker economies and job prospects. Numerous push and pull factors have concentrated Zhoushan's population distribution in developed towns and larger islands. Driving forces included exhaustion of fishery resources and policies from multi-level governments. Indeed, population migration in Zhoushan Archipelago was a local adaptation to dramatic changes in the natural environment and social context. 
Exhaustion of fishery resources

From 1999 onwards, fishery resources in Zhoushan Archipelago were nearing exhaustion, and fishery development slowed. Thus, the local government enacted policies to protect fisheries and transfer industries, leading to a shift in labour. Moreover, because of underdeveloped secondary and tertiary industries in some remote villages and small islands, residents there migrated to islands with more developed economies and industries for re-employment.

There were five main reasons for the exhaustion of fishery resources in Zhoushan. First, global warming increased carbon dioxide and temperatures in the ocean, destroying the marine food chain and affecting marine chemical composition and fishery production (Black et al., 2012). Second, the Three Gorges Dam project altered the runoff, hydrology, water chemistry, and depositional environment of the Yangtze River estuary and offshore waters, which changed the marine ecosystem and its distribution (Gong et al., 2006; Yang, Zhang, \& Xu, 2007), thereby reducing food availability for marine life. Third, land-derived pollutants in the Yangtze, Qiantang, and Yongjiang Rivers and pollutants discharged directly by industries and aquaculture along the coast have seriously contaminated the Zhoushan sea area. Fourth, long-term overfishing in Zhoushan has exceeded fisheries' self-renewal capacity. Finally, since the China-Korea Fishery Agreement took effect in 2001, fishing space in Zhoushan Archipelago has narrowed, making its fishery development much more difficult because of deteriorating aquaculture conditions and growing fishery costs.

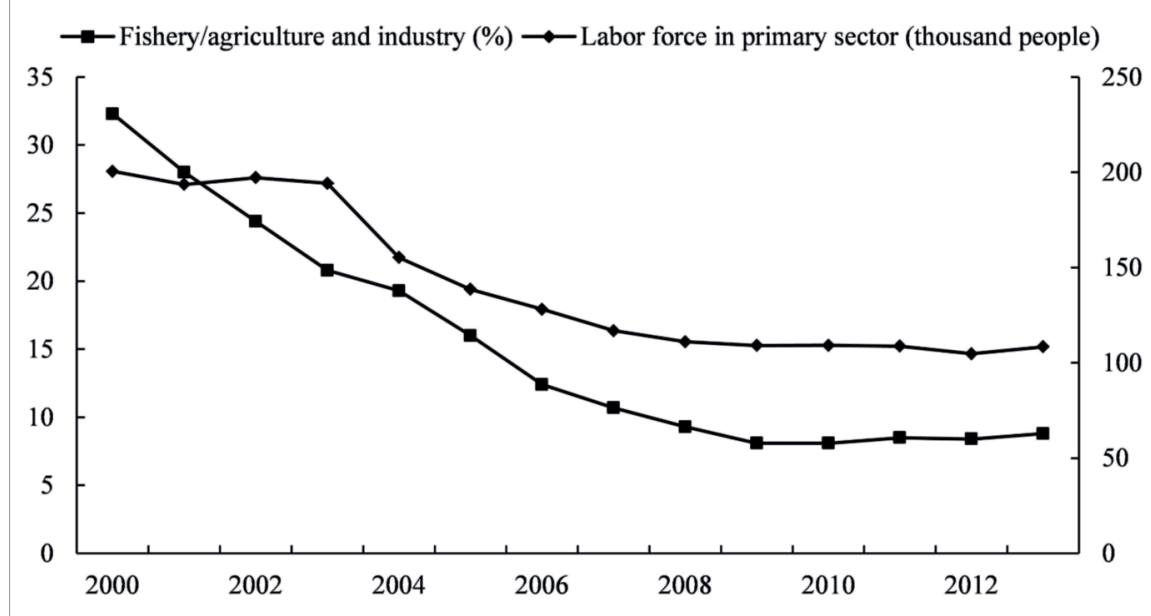

Figure 6: Changes in the fishery industry in Zhoushan from 2000 to 2013. Note: These data are from Zhoushan Statistical Yearbook of 2014.

Figure 6 shows that the proportion of fishery output in Zhoushan Archipelago's gross output of industry and agriculture decreased from $32.3 \%$ in 2000 to $8.8 \%$ in 2013 , with an annual reduction of $1.68 \%$. Labour engaged in the primary industry decreased from 200,500 people in 2000 to 108,400 people in 2013, with an annual reduction of 6,600 people. Re-employing the labour from the primary industry has been a major priority of the local government (Lou, Gu, Zhu, \& Liu, 2005). As an active response to a call by the central government, Zhoushan enacted policies to protect fishery resources and help fishermen engage in other industries, consequently promoting migration. The interaction between natural and human systems has had a significant effect on human activities (Kates, Travis, \& Wilbanks, 2012; Moser \& Hart, 2015).

Implementation of marine economic policies by multi-level governments

As a pilot area for developing China's marine economy, the central, provincial, and local governments have directly and indirectly guided Zhoushan Archipelago's development. The implementation of multi-level policies has strongly affected migration in Zhoushan. 
The Yangshan Deepwater Seaport project is a national policy that has promoted migration around Zhoushan's Qiqu Archipelago, outside the Hangzhou Bay estuary, and is the first seaport constructed on a micro-island in China, in order to meet the requirements of Shanghai's Free Trade Area development and the construction of an international shipping centre. Donghai Bridge, an important part of the project, connects Luchaogang town in Shanghai and Xiaoyangshan Island in Shengsi. Opened to traffic in 2005, this bridge cut a long ferry crossing to just a 30-minute car trip. Therefore, the seaport strengthened contact between Shanghai and the northern part of Zhoushan Archipelago. Industries in the seaport attracted a large immigrant population, and a great number of people from Zhoushan migrated to Shanghai. Moreover, a key provincial project, the Island-Mainland Link Project, started in Zhoushan in the 1990s. Since then, over 20 cross-sea bridges have been built between various islands. These bridges not only accelerated the linkage between land and sea and brought in a large external population but also connected the islands within the archipelago and promoted inter-island migration.

Table 5: Public infrastructure of each district in 2013.

\begin{tabular}{|l|l|l|l|l|}
\hline Index & Dinghai & Putuo & Daishan & Shengsi \\
\hline Highway mileage $(\mathrm{km})$ & 739.85 & 573.62 & 389.16 & 166.45 \\
\hline Expressway mileage $(\mathrm{km})$ & 32.13 & 0 & 0 & 0 \\
\hline Number of middle schools & 24 & 14 & 7 & 3 \\
\hline Number of primary schools & 25 & 12 & 13 & 7 \\
\hline Number of hospitals & 23 & 22 & 18 & 9 \\
\hline
\end{tabular}

Note: These data are from Zhoushan Statistical Yearbook of 2014.

The local government enacted a series of policies to encourage population migration and concentration, such as the 'Resettle Inhabitants from Small Islands and Develop Large Islands' policy to adapt to urbanization, attract external labour, and facilitate internal movement. One specific policy measure was to exchange rural housing for urban housing, which provided residences for immigrants, reduced pressure on these immigrants, and promoted migration more generally. Because of adverse living conditions on remote islands, residents migrated on their own initiative as well. Some remote villages and islands had problems with limited space, scarce fresh water, and high probability of natural disasters such as typhoons and tsunamis. In addition, public infrastructure, such as transportation, communication, power, medicine, and education, was inadequate or highly dispersed on small islands. Table 5 shows that public infrastructure in Daishan and Shengsi was inferior to that in Dinghai and Putuo in 2013. Furthermore, as marine fishing is a dangerous career, fishermen encouraged their children not to pursue this career but to instead receive an education and eventually obtain employment in the city (Wang \& Zhou, 2015). Since 2000, with guidance and support from the local government, residents of small islands successively migrated to large islands and urban areas. Residents from about eighteen small islands and remote villages on Zhoushan Island migrated to large islands and urban areas in Dinghai. In Putuo, 66.70\% of the population of sixteen small islands migrated, whereas in Daishan and Shengsi, 48.80\% and 65\% (respectively) of the population of small islands migrated to large islands (Wang \& Zhou, 2015).

With the selective inflow of people from the mainland to certain islands and directed migration inside the archipelago, the polarizing effect of island development became increasingly obvious. Smaller islands and less developed villages that were experiencing a population exodus fell further behind larger islands and developed towns. Due to a lack of public infrastructure, external investment, and supportive policies, those who are not in the position or do not have reasons to migrate to these 
developed regions, for example the poor or elderly or otherwise disadvantaged populations, are faced with threats to their survival. However, in recent years, by virtue of their relatively undisturbed natural environments, these smaller islands and less developed villages, such as Dongji Island, located in eastern Zhoushan, and Houtouwan village in Shengsi, have attracted many tourists. Tourism seems to be the key industry for these regions in the future. Nevertheless, these small islands lack sufficient public infrastructure and staff to serve tourists. If tourists pour in, not only will the quality of tourism be affected, but the local environment and culture may be destroyed as well. It is vital for the government to enact relevant policies to develop and protect these regions in order to reduce the impact of migration and ensure balanced development in the archipelago.

\section{Conclusion}

In this paper, we first utilized the rank-size rule to explore variations in population size distribution from two perspectives of the town and island. By means of the PMI and relevant literature, we then conducted a detailed semi-qualitative assessment of migratory dynamics. Finally, we discussed the driving forces of migration and made the following conclusions. First, Zhoushan's population distribution was more concentrated in developed towns and larger islands. In particular, the development of large islands was very prominent while that of small islands was insufficient. Second, population migration in Zhoushan Archipelago consisted of three main types, namely, intra-island migration, inter-island migration, and island-mainland migration. Inter-island migration and island-mainland migration were the two dominant types observed. Third, the driving forces mainly included the exhaustion of fishery resources and implementation of policies by multi-level governments. Generally speaking, it can be said that population migration in Zhoushan Archipelago has been a local adaptation to dramatic changes in the natural environment and social context.

Island capacity is limited. That is, an indefinite continuation of economic development on some islands would be impossible. For an archipelago such as Zhoushan with many scattered islands, the conventional hub-and-spoke pattern of development must be replaced with a netlike and multi-point pattern of development. Based on these conclusions and the individual features of each island, multi-level policies to inhibit or promote the three migration types can be made and implemented, so as to realize sustainable island development. In addition, the emergence of 'hollow' islands and villages means that island cultures are facing the threat of extinction. This study informs us which islands and villages are most likely to be hollowed out, thereby informing measures to preserve island cultures in the process of development and construction. This paper provides a new perspective, which can be utilized in other archipelagos, for research into island population and urbanization. However, more detailed data and materials and long-term field studies are necessary to further uncover more interesting features and causes of population migration in Zhoushan Archipelago.

\section{Acknowledgements}

This work was supported by the Key Program of the National Social Science Foundation of China (no. 14AZD124), National Natural Science Foundation of China (no. 51508498, and 41671533), and the Fundamental Research Funds for the Central Universities (no. 2016XZZX004-02).

\section{References}

Baldacchino, G. (2014). Islands and the offshoring possibilities and strategies of contemporary states: insights on/for the migration phenomenon on Europe's southern flank. Island Studies Journal, 9(1), 57-68.

Beckmann, M.J. (1958). City hierarchies and the distribution of city size. Economic Development and Cultural Change, 6(3), 243-248. https://doi.org/10.1086/449769

Black, R., Adger, W.N., Arnell, N.W., Dercon, S., Geddes, A., \& Thomas, D. (2012). The effect of environmental change on human migration. Global Environmental Change, 21(S1), S3-S11. 
Briskman, L., Fiske, L., \& Dimasi, M. (2012). Collateral damage: the impact of Australian asylum seeker policy on Christmas Islanders (2001-2011). Shima, 6(2), 99-115.

Burholt, V., Scharf, T., \& Walsh, K. (2013). Imagery and imaginary of islander identity: older people and migration in Irish small-island communities. Journal of Rural Studies, 31, 1-12. https://doi.org/10.1016/j.jrurstud.2013.01.007

Byravan, S., \& Rajan, S.C. (2006). Providing new homes for climate change exiles. Climate Policy, 6(2), 247-252. https://doi.org/10.1080/14693062.2006.9685599

Campbell, J. (2010). Climate change and population movement in Pacific Island Countries. In B. Burson (Ed.). Climate change and migration: South Pacific perspectives (pp. 29-50). Wellington: Institute of Policy Studies.

Carson, M.T., \& Hung, H.C. (2014). Semiconductor theory in migration: population receivers, homelands and gateways in Taiwan and Island Southeast Asia. World Archaeology, 46(4), 502-515. https://doi.org/10.1080/00438243.2014.931819

Chand, S. (2005). Labour mobility for sustainable livelihoods in Pacific island states. Pacific Economic Bulletin, 20(3), 63-76.

Chaolin, G., Liya, W., \& Cook, I. (2012). Progress in research on Chinese urbanization. Frontiers of Architectural Research, 1(2), 101-149. https://doi.org/10.1016/j.foar.2012.02.013

Chen, A., \& Gao, J. (2011). Urbanization in China and the coordinated development model: the case of Chengdu. The Social Science Joumal, 48(3), 500-513. https://doi.org/10.1016/j.soscij.2011.05.005

Chen, H.P. (2004). Path-dependent processes and the emergence of the rank size rule. The Annals of Regional Science, 38(3), 433-449. https://doi.org/10.1007/s00168-003-0151-z

Chen, M., Liu, W., \& Tao, X. (2013). Evolution and assessment on China's urbanization 1960-2010: under-urbanization or over-urbanization? Habitat International, 38, 25-33. https://doi.org/10.1016/j.habitatint.2012.09.007

Chen, Y., \& Liu, J. (1999). Fractals and fractal dimensions of city-size distributions. Human Geography, 14(2), 48-53.

Epstein, G.S., \& Nitzan, S. (2006). The struggle over migration policy. Journal of Population Economics, 19(4), 703-723. https://doi.org/10.1007/s00148-005-0021-3

Farbotko, C. (2010). Wishful sinking: disappearing islands, climate refugees and cosmopolitan experimentation. Asia Pacific Viewpoint, 51(1), 47-60. https://doi.org/10.1111/j.1467-8373.2010.001413.x

Fitzhugh, B., Gjesfjeld, E.W., Brown, W.A., Hudson, M.J., \& Shaw, J.D. (2016). Resilience and the population history of the Kuril Islands, Northwest Pacific: a study in complex human ecodynamics. Quaternary International, 419(17), 165-193. https://doi.org/10.1016/j.quaint.2016.02.003

Friedmann, J. (2006). Four theses in the study of China's urbanization. International Journal of Urban and Regional Research, 30(2), 440-451. https://doi.org/10.1111/j.1468-2427.2006.00671.x

Friese, H. (2012). Border economies: Lampedusa and the nascent migration industry. Shima, 6(2), 66-84.

Gong, G.C., Chang, J., Chiang, K.P., Hsiung, T.M., Hung, C.C., Duan, S.W., \& Codispoti, L. (2006). Reduction of primary production and changing of nutrient ratio in the East China Sea: effect of the Three Gorges Dam? Geophysical Research Letters, 33(7), 1944-8007. https://doi.org/10.1029/2006GL025800

Grydehøj, A. (2015). Island city formation and urban island studies. Area, 47(4), 429-435. https://doi.org/10.1111/area.12207

Grydehøj, A., Pinya, X.B., Cooke, G., Doratlı, N., Elewa, A., Kelman, I., Pugh, J., Schick, L., \& Swaminathan, R. (2015). Returning from the horizon: introducing urban island studies. Urban Island Studies, 1, 1-19. https://doi.org/10.20958/uis.2015.1

Guan, J., \& McElroy, J.L. (2012). The determinants of migration in small islands. Shima, 7(1), 80-95.

Guo, Z. (2014). On current situation of population urbanization in China: based on the 2010 population census data. Sociological Studies, 29(1), 10-24.

Hayward, P. (2015). The aquapelago and the estuarine city: reflections on Manhattan. Urban Island Studies, 1, 81-95. https://doi.org/10.20958/uis.2015.5 
Helgason, A., Pálsson, G., Pedersen, H.S., Angulalik, E., Gunnarsdóttir, E.D., Yngvadóttir, B., \& Stefánsson, K. (2006). mtDNA variation in Inuit populations of Greenland and Canada: migration history and population structure. American Journal of Physical Anthropology, 130(1), 123-134. https://doi.org/10.1002/ajpa.20313

Jacobson, J.L. (1988). Environmental refugees: a yardstick of habitability. Bulletin of Science, Technology \& Society, 8(3), 257-258. https://doi.org/10.1177/027046768800800304

Kates, R.W., Travis, W.R., \& Wilbanks, T.J. (2012). Transformational adaptation when incremental adaptations to climate change are insufficient. Proceedings of the National Academy of Sciences, 109(19), 7156-7161. https://doi.org/10.1073/pnas.1115521109

Kojima, R. (1996). Introduction: population migration and urbanization in developing countries. The Developing Economies, 34(4), 349-369. https://doi.org/10.1111/j.1746-1049.1996.tb01176.x

Lai, S.Y., Chandren, S., Efendi, J., Chin Siong, H.O., \& Nur, H. (1995). The age of migration: international population movements in the modern world. International Labour Review, 49(3), 537-542.

Lee, E.S. (1966). A theory of migration. Demography, 3(1), 47-57. https://doi.org/10.2307/2060063

Lin, G.C. (1998). China's industrialization with controlled urbanization: anti-urbanism or urban-biased? Issues \& Studies, 34(6), 98-116.

Lin, G.C. (2007). Chinese urbanism in question: state, society, and the reproduction of urban spaces. Urban Geography, 28(1), 7-29. https://doi.org/10.2747/0272-3638.28.1.7

Liu, J. (2014). The study on social mobility of island fishing village population investigation on the fishing village of Changdao county of Shandong Province. Masters Dissertation. Ocean University of China.

Locke, J.T. (2009). Climate change-induced migration in the Pacific region: sudden crisis and long-term developments. The Geographical Journal, 175(3), 171-180. https://doi.org/10.1111/j.1475-4959.2008.00317.x

Lonergan, S. (1998). The role of environmental degradation in population displacement. Environmental Change \& Security Project Report, 4(4), 5-15.

Lou, D., Gu, S., Zhu, B., \& Liu, S. (2005). Analysis on industrial succession and resource bases of islands area: Zhoushan Archipelago as the case study. Economic Geography, 25(4), 483-487.

Loyd, J.M., \& Mountz, A. (2014). Managing migration, scaling sovereignty on islands. Island Studies Journal, 9(1), 23-42.

Massey, D.S., Arango, J., Hugo, G., Kouaouci, A., Pellegrino, A., \& Taylor, J.E. (1994). An evaluation of international migration theory: the North American case. Population and Development Review, 20(4), 699-751. https://doi.org/10.2307/2137660

Mcleman, R., \& Smit, B. (2006). Migration as an adaptation to climate change. Climatic Change, 76(1), 31-53. https://doi.org/10.1007/s10584-005-9000-7

Mortreux, C., \& Barnett, J. (2009). Climate change, migration and adaptation in Funafuti, Tuvalu. Global Environmental Change, 19(1), 105-112. https://doi.org/10.1016/j.gloenvcha.2008.09.006

Moser, S.C., \& Hart, J.A.F. (2015). The long arm of climate change: societal teleconnections and the future of climate change impacts studies. Climatic Change, 129(1-2), 13-26. https://doi.org/10.1007/s10584-015-1328-z

Myers, N. (2001). Environmental refugees. Population \& Environment, 19(2), 167-182. https://doi.org/10.1023/A:1024623431924

Myers, N. (2002). Environmental refugees: a growing phenomenon of the 21st century. Philosophical Transactions of the Royal Society B: Biological Sciences, 357(1420), 609-613. https://doi.org/10.1098/rstb.2001.0953

National Bureau of Statistics of China (NBS). (2001). Major figures on 2000 population census of China. Beijing, China: China Statistical Press.

National Bureau of Statistics of China (NBS). (2011). Major figures on 2010 population census of China. Beijing, China: China Statistical Press. 
National Bureau of Statistics of China (NBS). (2014). China statistical yearbook 2014. Beijing, China: China Statistics Press.

Qi, W., \& Liu, S. (2015). Research on the rank-size distribution rule of China's urban floating population. Geographical Research, 34(10), 1981-1993.

Qiu, S., Yue, W., Zhang, H., \& Qi, J. (2017). Island ecosystem services value, land-use change, and the National New Area Policy in Zhoushan Archipelago, China. Island Studies Journal, 12(2). http://doi.org/10.24043/isj.20

Ravenstein, E.G. (1885). The laws of migration. Journal of the Statistical Society of London, 48(2), 167-235. https://doi.org/10.2307/2979181

Shaw, B.J., Summerhayes, G.R., Buckley, H.R., \& Baker, J.A. (2009). The use of strontium isotopes as an indicator of migration in human and pig Lapita populations in the Bismarck Archipelago, Papua New Guinea. Journal of Archaeological Science, 36(4), 1079-1091. https://doi.org/10.1016/j.jas.2008.12.010

Shen, J., Feng, Z., \& Wong, K.Y. (2006). Dual-track urbanization in a transitional economy: the case of Pearl River Delta in South China. Habitat International, 30(3), 690-705. https://doi.org/10.1016/j.habitatint.2005.04.003

Stark, O., Micevska, M., \& Mycielski, J. (2009). Relative poverty as a determinant of migration: evidence from Poland. Economics Letters, 103(3), 119-122. https://doi.org/10.1016/j.econlet.2009.02.006

Steyn, G. (2015). The impacts of islandness on the urbanism and architecture of Mombasa. Urban Island Studies, 1, 55-80. https://doi.org/10.20958/uis.2015.4

Triandafyllidou, A. (2014). Multi-levelling and externalizing migration and asylum: lessons from the southern European islands. Island Studies Journal, 9(1), 7-22.

Wang, G., Qin, Z., \& Cheng, L. (2012). Spatial distribution of population migration in China in the 1990s. Scientia Geographica Sinica, 32(3), 273-281.

Wang, H. (2004). The evolvement law of spatial structure of the Chang Shan Archipelagos, its driving mechanisms and countermeasures of adjustment and control. Masters Dissertation. Liaoning Normal University.

Wang, J., Xia, Q., \& Wang, S. (2012). Research on migration history of Zhoushan Islands and ways to promote migration. Journal of Zhejiang International Maritime College, 8(2), 15-25.

Wang, J., \& Zhou, Y. (2015). Analysis and reflections on the island resettlement policy: taking the 'Resettle Inhabitant from Small Islands and Develop Large Islands' policy in Zhoushan as an example. Journal of Zhejiang Ocean University (Humanities Science), 32(5), 37-42.

World Bank and Development Research Center of the State Council (DRCSC). (2013). China 2030: building a modern, harmonious, and creative society. Washington, DC, USA: World Bank Publications.

Xu, X., Zhou, Y., \& Ning, Y. (2009). Urban geography, 2nd edition. Beijing: Higher Education Press.

Yang, S., Zhang, J., \& Xu, X. (2007). Influence of the Three Gorges Dam on downstream delivery of sediment and its environmental implications, Yangtze River. Geophysical Research Letters, 34(10). https://doi.org/10.1029/2007GL029472

Zhang, H. (2012). Economic context of marine living environment of the island hollow and countermeasures: take Zhoushan Islands as an example. Architecture \& Culture, 6, 91-93.

Zhang, L., \& Zhao, S.X. (2003). Reinterpretation of China's under-urbanization: a systemic perspective. Habitat International, 27(3), 459-483. https://doi.org/10.1016/S0197-3975(02)00071-1

Zhao, J., Tian, Z., Huang, P., \& Wu, S. (2012). Population change and prediction of big Changshan Island town. Ocean Development and Management, 7, 42-46.

Zhoushan Bureau of Statistics. (2015). Zhoushan statistical yearbook 2015. Beijing, China: China Statistical Press.

Zhoushan Bureau of Statistics. (2002). Zhoushan statistical yearbook 2002. Beijing, China: China Statistical Press.

Zipf, G.K. (1946). The P1 P2/D hypothesis: on the intercity movement of persons. American Sociological Review, 11(6), 677-686. https://doi.org/10.2307/2087063 